\title{
Skin rashes and stomatitis due to parenteral treatment of rheumatoid arthritis with sodium aurothiomalate
}

\author{
A Svensson, J Theander
}

\begin{abstract}
In a prospective study of 45 patients with rheumatoid arthritis mucocutaneous symptoms and signs were evaluated before and during treatment with intramuscular sodium aurothiomalate (Myocrisin). The work, performed in close collaboration between dermatology and rheumatology departments, showed that there was no significant increase in mucocutaneous side effects in patients with pre-existing mucocutaneous disease.

It is concluded that pre-existing dermatitis is not a contraindication for treatment with gold salts and that a previous mucocutaneous reaction to gold salts is not an absolute contraindication for a new trial of chrysotherapy.
\end{abstract}

Parenteral gold salts have been used in the treatment of rheumatoid arthritis (RA) since the 1920 s. $^{1}$ Its mechanisms of action are still not known ${ }^{2}$ but recent investigations suggest that it has immunoregulatory effects. ${ }^{3}$ Skin rashes and stomatitis are the most common side effects of treatment with gold. ${ }^{4}$ Side effects, which can appear at any time during the course of treatment, range from an isolated pruritus to a life threatening but rare exfoliative dermatitis. ${ }^{5}$ The frequency of occurrence of mucocutaneous eruptions has been reported to be as high as $53 \%,{ }^{6}$ but other workers, have reported considerably lower occurrences. ${ }^{7}$

In the present prospective study mucocutaneous reactions were evaluated before and during the course of parenteral treatment of patients with RA with sodium aurothiomalate (Myocrisin). The clinical and histological findings are described and their relevance discussed.

\section{Patients and methods}

Forty five consecutive patients with classic or definite RA, defined according to the criteria of the American Rheumatism Association, were selected for the study. ${ }^{8}$ Of the 45 patients, 32 were women and 13 men (mean age 52.2 years, range 24-73). The average duration of disease was 10.4 years (range $0.5-47$ ). Patients were selected because their disease was severe and unresponsive to other treatment. A standard chrysotherapy regimen of intramuscular sodium aurothiomalate $20-50 \mathrm{mg}$ weekly to $1 \mathrm{~g}$ was given. After a dose of $1 \mathrm{~g}$ was reached, if the response was satisfactory, maintenance doses of 20-50 mg every other week were injected for about 20 weeks, followed by injection every third and then every fourth week for an indefinite period of time. When rechallenging patients with previous mucocutaneous reactions to gold salts, the same regimen was followed but the weekly dose was increased only every third week.

The erythrocyte sedimentation rate, haemoglobin, total white blood cell count, thrombocytes, and urine analysis for proteinuria and haematuria were determined before every injection. IgE levels were determined with a radioimmunoassay and were measured again if the patient developed a mucocutaneous reaction. Serum protein was determined by electrophoresis and a Rose-Waaler test for rheumatoid factor was performed. Liver enzymes, $\mathrm{C}$ reactive protein, and antinuclear antibodies were measured at the start of the study and every third month.

All patients were examined at the department of dermatology before starting treatment with sodium aurothiomalate. Mucocutaneous symptoms and signs were listed on a special form. All patients were patch tested with the standard International Contact Dermatitis Research Group series and aqueous $0.001 \%$ potassium dicyanoaurate. Patients with eczema were also patch tested with their own products and other sensitisers and compounds. Patch testing was performed with Finn Chambers on Scanpor with an application time of $\mathbf{4 8}$ hours; the tests were read 72 hours after application.

Ten of the patients had been treated previously with chrysotherapy and three had discontinued treatment with gold as a result of skin reactions.

Table 1 shows that in total 21 patients had mucocutaneous symptoms before starting treatment with sodium aurothiomalate. Xerostomia and keratoconjunctivitis sicca are not included in these symptoms.

All patients were questioned about the presence of rash, pruritus, mouth ulcers, and other unusual symptoms before every injection.

Table 1 Mucocutaneous symptoms and diseases in 21 patients with $R A$ before beginning treatment with gold. One patient had allergic contact dermatitis, seborrhoeic dermatitis, and unspecified mouth irritation. All the others had only one diagnosis or had only one symptom

\begin{tabular}{ll}
\hline Diagnosis or symptoms & Number of patients \\
\hline Allergic contact dermatitis & 6 \\
Psoriasis & 4 \\
Seborrhoeic dermatitis & 3 \\
Unspecified eczema & 2 \\
Generalised pruritus & 2 \\
Lichen ruber & 1 \\
Neurodermatitis & 1 \\
Chronic urticaria & 1 \\
Ichthyosis vulgaris & 1 \\
Unspecified mouth blisters & 1 \\
Unspecified mouth irritation & 1 \\
\hline
\end{tabular}
S-291 85 Kristianstad, J Theander

Correspondence to: Dr Svensson. 
Patients with an increase in the severity of their mucocutaneous disease or with other mucocutaneous symptoms when treated with injections of sodium aurothiomalate were regularly seen at the department of dermatology. Skin eruptions or stomatitis for which no other specific diagnoses could be established was defined as a side effect to gold treatment. In every patient with skin lesions first appearing when receiving chrysotherapy or with an increase in the severity of previous skin disease, $3 \mathrm{~mm}$ punch biopsy specimens were obtained for histological and direct immunofluorescence study. No biopsy samples were taken from the mouth.

All patients with mucocutaneous symptoms related to treatment with sodium aurothiomalate were retested with potassium dicyanoaurate.

\section{STATISTICAL METHODS}

For comparison between the groups, Fisher's exact test and the Wilcoxon rank sum test were used. A significant difference in the results was assigned if $\mathrm{p}<0.05$.

\section{Results}

A demographic comparison was made between patients who developed mucocutaneous reactions to sodium aurothiomalate and those who did not. No statistically significant difference in age, duration of disease, or sex ratio was found.

The Rose-Waaler test was positive in 36 $(80 \%)$ of the patients whereas $13(29 \%)$ had positive antinuclear antibodies. At the start of treatment the patients had a mean erythrocyte sedimentation rate of $56.7 \mathrm{~mm} / \mathrm{h}$ and a mean $C$ reactive protein of $56.0 \mathrm{mg} / \mathrm{l}$. According to radiographs taken before the study $37(82 \%)$ had a classical erosive RA. At the start of chrysotherapy there were no statistically significant differences between the two groups with respect to rheumatoid factor, erythrocyte sedimentation rate, $C$ reactive protein, antinuclear antibodies, erosive disease, or levels of immunoglobulins.

The chrysotherapy was withdrawn from 24 patients (53\%) during the study period. Side effects were the most common reason for withdrawing treatment. Of the 13 patients (29\%) with side effects, nine $(20 \%)$ had a mucocutaneous reaction. The four remaining patients were withdrawn because of thrombocytopenia (one), proteinuria (one), persistent diarrhoea (one), and a lupus-like syndrome (one). Chrysotherapy was stopped in nine (20\%) patients as it had no effect and in two patients as a result of an exacerbation of their previous skin disease.

The 45 patients were treated for an average of 55 weeks. Their mean total dose at the end of the study was $1522 \mathrm{mg}$. Nine patients with mucocutaneous reactions developed these after 4-21 weeks of treatment (average 13 weeks). Their average cumulative dose was $512 \mathrm{mg}$ (range 60-970 mg).

Of the 11 patients who were withdrawn from treatment with sodium aurothiomalate because of mucocutaneous symptoms, we regarded only nine as having side effects to treatment with gold. Table 2 summarises the clinical distribution, histological, and immunofluorescence

Table 2 Clinical distribution, histological, and immunofluorescent features in the patients with mucocutaneous side effects to treatment with gold

\begin{tabular}{|c|c|c|c|c|c|c|}
\hline $\begin{array}{l}\text { Patient } \\
\text { No }\end{array}$ & Sex & $\begin{array}{l}\text { Age } \\
\text { (years) }\end{array}$ & Mucocutaneous findings & Distribution & Histological features & Immunofluorescence features \\
\hline 1 & $\mathbf{M}$ & 70 & Lichen ruber-like lesions & $\begin{array}{l}\text { Trunk, arms, legs, } \\
\text { axillae }\end{array}$ & $\begin{array}{l}\text { Superficial band-like } \\
\text { lymphohistiocytic } \\
\text { infiltrate, increased } \\
\text { number of Civatte bodies } \\
\text { and diminished granular } \\
\text { zone }\end{array}$ & $\begin{array}{l}\text { Civatte bodies with deposits } \\
\text { of IgA, IgM, and } \\
\text { fibrinogen. Deposits of } \\
\text { fibrinogen and granular C3 } \\
\text { along basal membrane zone }\end{array}$ \\
\hline 2 & $\mathbf{F}$ & 69 & Stomatitis & Mouth & Not performed & Not performed \\
\hline 3 & $\mathbf{F}$ & 60 & $\begin{array}{l}\text { Non-specific papules } \\
\text { and plaques, stomatitis }\end{array}$ & Trunk, arms, mouth & $\begin{array}{l}\text { Superficial perivascular } \\
\text { dermatitis }\end{array}$ & $\begin{array}{l}\text { Ciratte bodies with deposits } \\
\text { of IgM, granular C3, and } \\
\text { fibrinogen. Deposits of } \\
\text { fibrinogen and granular C3 } \\
\text { along basal membrane zone }\end{array}$ \\
\hline 4 & $\mathbf{M}$ & 59 & $\begin{array}{l}\text { Non-specific eczema-like } \\
\text { lesions }\end{array}$ & $\begin{array}{l}\text { Lower legs, backs } \\
\text { of the hands, } \\
\text { right lower arm }\end{array}$ & $\begin{array}{l}\text { Superficial perivascular } \\
\text { dermatitis with foci of } \\
\text { spongiosis }\end{array}$ & $\begin{array}{l}\text { Diffuse upper dermal deposits } \\
\text { of fibrinogen and granular } \\
\text { C3, and sparse deposits of } \\
\text { IgM in small vessels in } \\
\text { dermis }\end{array}$ \\
\hline 5 & $\mathbf{F}$ & 58 & $\begin{array}{l}\text { Exanthema. Slight } \\
\text { conjunctivitis }\end{array}$ & $\begin{array}{l}\text { Trunk, axillae, } \\
\text { neck, palms }\end{array}$ & - $^{*}$ & Negative \\
\hline 6 & $\mathbf{F}$ & 53 & $\begin{array}{l}\text { Pityriasis rosea-like } \\
\text { lesions }\end{array}$ & $\begin{array}{l}\text { Trunk, lower legs, } \\
\text { arms }\end{array}$ & $\begin{array}{l}\text { Superficial and } \\
\text { deep perivascular } \\
\text { lymphohistiocytic infiltrate } \\
\text { with foci of spongiosis }\end{array}$ & $\begin{array}{l}\text { Civatte bodies with deposits } \\
\text { of IgM. Sparse deposits of } \\
\text { granular C3 and marked } \\
\text { deposits of fibrinogen } \\
\text { along basal membrane } \\
\text { zone, perivascular deposits } \\
\text { of fibrinogen in dermis }\end{array}$ \\
\hline 7 & $\mathbf{M}$ & 49 & $\begin{array}{l}\text { Lichen ruber-like } \\
\text { lesions, stomatitis }\end{array}$ & $\begin{array}{l}\text { Trunk, arms, legs, } \\
\text { hands, feet }\end{array}$ & $\begin{array}{l}\text { Superficial and } \\
\text { deep perivascular } \\
\text { lymphohistiocytic infiltrate } \\
\text { with neutrophils, } \\
\text { increased number of } \\
\text { Civatte bodies and } \\
\text { diminished granular zone }\end{array}$ & $\begin{array}{l}\text { Civatte bodies with deposits } \\
\text { of fibrinogen. Deposits of } \\
\text { granular C } 3 \text { and fibrinogen } \\
\text { along basal membrane zone }\end{array}$ \\
\hline 8 & $\mathbf{F}$ & 42 & $\begin{array}{l}\text { Porphyria cutanea } \\
\text { tarda-like lesions }\end{array}$ & $\begin{array}{l}\text { Dorsal parts of } \\
\text { hands and fingers }\end{array}$ & $\begin{array}{l}\text { Intraepidermal bulla with } \\
\text { sparse neutrophilic } \\
\text { infiltration of the dermis }\end{array}$ & Not performed \\
\hline 9 & $\mathbf{F}$ & 29 & $\begin{array}{l}\text { Pityriasis rosea-like } \\
\text { lesions }\end{array}$ & $\begin{array}{l}\text { Face, lower legs, } \\
\text { lower arms, feet }\end{array}$ & $\begin{array}{l}\text { Superficial perivascular } \\
\text { lymphohistiocytic infiltrate } \\
\text { with foci of spongiosis, } \\
\text { extravasated erythrocytes } \\
\text { and focal parakeratosis }\end{array}$ & $\begin{array}{l}\text { Deposits of granular C3 } \\
\text { along basal membrane zone }\end{array}$ \\
\hline
\end{tabular}


features of the patients. Only the patient with porphyria cutanea tarda-like eruptions and the patient with isolated stomatitis had no pruritus.

Exacerbation of pre-existing skin disease which was not considered to be a reaction to the drug was registered in two patients. A woman with severe psoriasis developed an exacerbation of her skin disease, which made continued chrysotherapy impossible after receiving 290 $\mathrm{mg}$ sodium aurothiomalate. Another woman with an unspecified eczema was withdrawn from the trial after $140 \mathrm{mg}$ sodium aurothiomalate because of an exacerbation of her eczema.

Three of the 21 patients with mucocutaneous symptoms before treatment with sodium aurothiomalate developed dermatitis; one also developed a concomitant stomatitis. These three patients had neurodermatitis, allergic contact eczema, and pruritus before the start of the study.

Thus only five of the 21 patients in the group with mucocutaneous symptoms before had to stop treatment with sodium aurothiomalate because of either side effects to gold salts or an exacerbation of their previous disease. In the other group of 24 patients without mucocutaneous symptoms before treatment, 10 developed a mucocutaneous reaction considered to be a reaction to gold. There was no significant difference in the occurrence of mucocutaneous reactions between the two groups.

Of the three patients who had experienced mucocutaneous reactions with previous chrysotherapy, one again developed dermatitis after $970 \mathrm{mg}$ sodium aurothiomalate (patient 4). The reinstitution of gold salts to the other two patients was without problems. One of the patients is still receiving treatment and is in remission; the other stopped receiving treatment because of a lack of effect after $1170 \mathrm{mg}$ sodium aurothiomalate.

None of our patients with mucocutaneous reactions to gold salts developed a contact allergy when tested after the adverse event.

\section{Discussion}

In this study nine patients developed mucocutaneous symptoms considered to be side effects to treatment with sodium aurothiomalate. As in previous studies the most commonly found skin lesions were non-classifiable papular or macular rashes and lichen ruber-like and pityriasis rosaea-like lesions. ${ }^{45}$ 9-11 One patient developed porphyria cutanea tarda-like lesions with multiple scars and bullae or vesicles on the dorsal parts of the fingers and hands. According to anamnestic data the patient experienced no exacerbation from light, but minor trauma did cause an exacerbation. The clinical findings were very suggestive of porphyria cutanea tarda, but the histological investigation showed an intraepidermal bulla and not a subepidermal lesion as in porphyria cutanea tarda. Liver function tests and analyses of urinary uroporphyrin and urinary coproporphyrin gave normal results. The patient refused analyses of faecal porphyrins. The symptoms resolved after about 10 months.

Drug stomatitis has been reported in between
$2 \%$ and $13 \%$ of patients treated with systemic gold salts. ${ }^{12}$ In our study two patients (4\%) developed non-specific ulcerations of the buccal mucosa. One of the patients had only lesions of the mouth, the other also had lichen ruber-like skin lesions. In the two patients the mouth lesions disappeared in about a month, but the skin lesions in the patient with lichen ruber are still active and persisting 20 months after stopping treatment with sodium aurothiomalate.

In the eight patients with a rash, the median duration of cutaneous symptoms was six weeks, with a range of 10 days to 20 months. The symptoms usually clear within three to four months, ${ }^{11}$ but can persist for some years. ${ }^{911}$

Differentiation between idiopathic lichen ruber and lichenoid eruption as a result or drug treatment is difficult as there are no totally discriminant histological criteria. ${ }^{13}$ In our two patients with lichen ruber-like skin lesions the granular zone was diminished and in one of the patients a deep perivascular infiltrate was present. These findings favour lichenoid eruption as a result of drug treatment. ${ }^{11}{ }^{13}$ However, no eosinophils, focal interruption of the granular layer, nor focal parakeratosis was present, criteria also more often found in lichenoid eruption as a result of drug treatment. ${ }^{11}{ }^{13}$ In these two patients with lichen ruber-like lesions the histological examination was helpful in differentiating the diagnosis. In the other patients the diagnostic value of the histological examinations was minimal.

Immunofluorescent investigations were performed for seven patients (table 2). In six of these there were positive findings and in four poikiloderma of Civatte was found in the papulary dermis. The number of patients is too small to determine the value of this investigation but the results are interesting and it is worth studying a larger patient group.

A relation between the presence of IgE antibodies to gold and mucocutaneous lesions has been shown by Bretza et al. ${ }^{14}$ This study could not show increasing serum IgE levels in the patients with mucocutaneous side effects to gold treatment, nor was there any correlation between high serum IgE levels and mucocutaneous lesions.

Caspi et al reported that all 31 patients with skin eruptions as a result of treatment with gold salts entered a concomitant clinical and laboratory remission when treated with sodium aurothioglucose. ${ }^{15}$ Of our eight patients with gold induced dermatitis treated with sodium aurothiomalate, only two entered clinical and laboratory remission ${ }^{16}$ at the same time as the skin reaction appeared (patients 7 and 9). Patient 7 is still in remission after 15 months, whereas patient 9 had an exacerbation of the dermatitis after 11 months

Gold salts are still among the most effective drugs for treating RA. The most common side effect induced by gold is a mucocutaneous reaction. It is often very difficult to evaluate if there is any connection between the skin reaction and the treatment with gold. We find that a close collaboration between the rheumatologist and the dermatologist is of great value in evaluating skin diseases and their relation to 
chrysotherapy. With such a collaboration treatment with gold salts should not be a contraindication when there is pre-existing dermatitis ${ }^{5}$ because in most patients it is possible to distinguish the pre-existing dermatitis from adverse effects of the drug. We also consider that previous adverse mucocutaneous reactions to gold salts are not an absolute contraindication for a new trial of chrysotherapy. ${ }^{17}$ However, rechallenging a patient must be performed cautiously as a life threatening exfoliative dermatitis can appear. ${ }^{5}$

1 Forestier J M. L'aurothérapie dans les rheumatismes chroniques. Bull Soc Med Hop Paris 1929; 53: 323-7.

2 Sigler J W. Parenteral gold in the treatment of rheumatoid arthritis. Am F Med 1983; 75: 59-62.

3 Bluhm G B. The mechanisms of action of conventional chrysotherapy. F Rheumatol 1982; 9 (suppl 8): $10-7$.

4 Gibbons R B. Complications of chrysotherapy. A review of recent studies. Arch Intern Med 1979; 139: 343-6.

5 Thomas I. Gold therapy and its indications in dermatology. 7 Am Acad Dermatol 1987; 16: 845-54.

6 Browning J S, Rice R M, Lee W V, Baker L M. Gold therapy in rheumatoid arthritis. $N$ Engl f Med 1947; 237: 428-31.
7 Rainer F. Unerwünschte Wirkungen der Goldtherapie. Wien Klin Wochenschr Suppl 1984; 156: 40-4.

8 Ropes M W, Bennett G A, Cobb S, Jacox R, Jessar R A. 1958 Revision of diagnostic criteria for rheumatoid arthritis. Bull Rheum Dis 1958; 9: 175-6.

9 Bogg A. Skin complications of gold treatment. Acta Rheum Scand 1958; 4: 86-97.

10 Hofmann C, Burg G, Jung C. Nebenwirkungen der Goldtherapie an der Haut. In: Holzmann $H$, Altmeyer $P$, Marsch $\mathrm{W}$, Vozel $\mathrm{H}$, eds. Dermatologie und Rheuma. Berlin: Springer Verlag, 1987: 472-8.

11 Penneys N S, Ackerman B, Gottlieb N L. Gold dermatitis. A clinical and histopathological study. Arch Dermatol 1974; 109: 372-6.

12 Glenert U. Drug stomatitis due to gold therapy. Oral Surg 1984; 58: 52-6.

13 Van den Haute V, Antoine J L, Lachapelle J M. Histopathological discriminant criteria between lichenoid drug eruption and idiopathic lichen planus: retrospective study on selected samples. Dermatologica 1989; 179: 10-3.

14 Bretza J, Wells I, Novey H S. Association of IgE antibodies to sodium aurothiomalate and adverse reactions to chrysoto sodium aurothiomaie and adverse re 7 Med 1983; 74: therapy

15 Caspi D, Tishler M, Yaron M. Association between gold induced skin rash and remission in patients with rheumatoid arthritis. Ann Rheum Dis 1989; 48: 730-2.

16 Pinals R S, Masi A T, Larsen R A, and the Subcommittee for Criteria of Remission in RA of the ARA Diagnostic and Theria of Re Therapeutic Criteria Committee. Preliminary criteria for clinical remission in

17 Klinefelter H F. Reinstitution of gold therapy in rheumatoid arthritis after mucocutaneous reactions. I Rheumatol 1975 2: 21-7. 